\title{
¿Por qué creo que la artroscopia de muñeca es fundamental para la Cirugía de la Mano?
}

\author{
M. DEL Cerro \\ Unidad de Cirugía de Mano y Muñeca. Hospital Beata María Ana. Madrid. España.
}

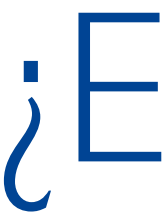

stá llegando la cirugía abierta de la muñeca a su fin? Hace muchos años era impensable no abrir una rodilla para arreglar un ligamento cruzado y actualmente todos los cirujanos utilizan la cirugía artroscópica para su reparación.

¿Seguimos el mismo camino en la muñeca? La respuesta nos la dará el tiempo pero mucho nos tememos, y nos alegramos por ello las personas del mundo de la Cirugía de la Mano, que este camino que no ha hecho más que empezar, es un viaje sin retorno.

En 1992 permanecí una semana en Gerona con el recientemente fallecido Dr. Fernando Fonseca que estaba comenzando a tratar lesiones complejas de la muñeca mediante cirugía artroscópica. No se había iniciado la necesaria "epidemia" de la osteosíntesis de las fracturas de extremidad distal del radio y Fernando ya las operaba con ayuda artroscópica sintetizando los pequeños fragmentos intrarticulares utilizando... Tissucol. Reparaba los ligamentos triangulares con una aguja intramuscular y un hilo de sutura dentro de la misma y realizaba otras técnicas que sonaban a ciencia ficción para los traumatólogos clásicos. Tenía muy claro que ese era el porvenir de la cirugía de la muñeca y tuve la sensación de estar trabajando durante 7 días con un gran cirujano y un hombre con una increible visión del futuro. Al año siguiente, 1993, organizamos conjuntamente nuestro primer curso de artroscopia de muñeca en La Coruña.

A pesar de la reticencia que tienen todavía muchos servicios de Traumatología hacia la artroscopia de muñeca y en general hacia la Cirugía de la Mano, los buenos resultados que se van obteniendo, gracias a la mejoría de las técnicas y la cada vez más completa formación de los cirujanos que se dedican a este campo, hacen que la "mentalidad de nuestros mayores" vaya cambiando poco a poco y que, no sin gran esfuerzo, podamos conseguir los objetivos deseados.

Cada vez son más numerosos los cursos monográficos dedicados a la artroscopia de muñeca y cada vez más frecuentes las publicaciones sobre este tema. Existe una Sociedad Europea de Artroscopia de Muñeca (EWAS), lo que demuestra la importancia que se da en el mundo entero a esta técnica.

En septiembre del 2014, la Revista Española de Artroscopia y Cirugía Articular ha publicado un número monográfico sobre artroscopia de muñeca en el que podemos leer y disfrutar las múltiples novedades y los grandes avances de este campo.

En la brillante y nueva etapa editorial de la Revista Iberoamericana de Cirugía de la Mano han sido muchos los artículos de artroscopia de muñeca que han aparecido.

Es numerosa la patología articular de la muñeca que precisa tratamiento abierto... por el momento, y es mucha la que se está solucionando artroscópicamente. Las técnicas son cada día más complejas. Lo que inició Fernando Fonseca, hoy día es una realidad y algunas ligamentoplastias, artrodesis, reanclajes a fóvea del FCT, y parte de la patología trapeciome- 
tacarpiana la hacemos de una manera sistemática por artroscopia. Se ha mostrado también como una herramienta muy útil en el diagnóstico de lesiones que pasan desapercibidas en las pruebas de imagen.

En mi opinión, su aprendizaje es imprescindible para todos los especialistas en Cirugía de la Mano que tenemos la obligación de formarnos continuamente y transmitir nuestros conocimientos.

Animo a todos a iniciar o continuar su preparación en este campo.

Debemos seguir luchando por el progreso e imponer el progreso demostrando que es una realidad.

Debemos convencernos y convencer a los demás que este es el auténtico camino para mejorar los resultados de nuestra actividad quirúrgica y asistencial.

Debemos hacerlo, porque si no lo hacemos nosotros, ¿quién lo va a hacer?

M. del Cerro Hospital Beata María Ana. Madrid. España migueldelcerro@yahoo.es 